\title{
Corrosion of steel fibre reinforced concrete (SFRC) subjected to simulated stray direct (DC) interference
}

\section{Kangkang Tang}

kangkangtang@gmail.com(kangkangtang@gmail.com; kangkang.tang@brunel.ac.uk)

Brunel University London, Howell Building, Department of Civil and Environmenta, UB8 3PNUB8 3PH, London, Uxbridge, United Kingdom

Abstract

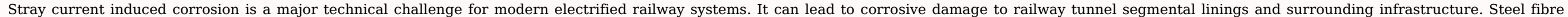

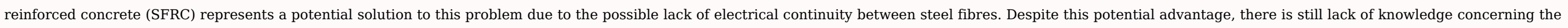

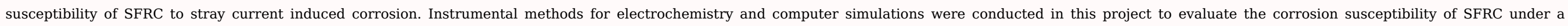

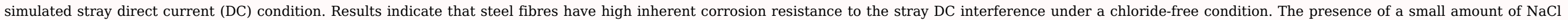
however can lead to enhanced stray DC-induced corrosion.

Keywords: Steel fibre reinforced concrete; Tafel polarization; EIS; Cyclic voltammetry; Passivity; Pitting corrosion; Boundary element method

Nomenclature

$A$

Exposed anode area $\left(\mathrm{cm}^{2}\right)$

$\beta_{a^{\prime}} \beta_{b}$

Anodic and cathodic Tafel constants/gradients

Steel passive layer capacitance $\mathrm{CPE}\left(\mathrm{S} \cdot \mathrm{s}^{\mathrm{n}} \mathrm{cm}^{-2}\right)$

$C_{c}$

Double layer capacitance CPE $\left(\mathrm{S} \cdot \mathrm{s}^{\mathrm{n}} \mathrm{cm}^{--2}\right)$

CR

Corrosion rate (mm/year)

$E_{\text {corr }}$

Corrosion potential (V)

Measured current from the circuit or the net electron flow (A)

$I_{\text {total }}$

Total stray current (A) 
$I_{\text {corr }}$

Corrosion current (A)

$i_{\text {corr }}$

Corrosion current density $\left(\mathrm{A} / \mathrm{cm}^{2}\right)$

L

Distance between substations $(\mathrm{km})$

$\eta_{e, \underline{\underline{a}}, \eta^{\prime}, c}$

Anodic and cathodic overpotentials (V) from $E e, a$ and $E e, c$

$r_{R}$

Resistance of the running tracks $(\Omega / \mathrm{km})$

$r_{T}$

Track-earth resistance $(\Omega \cdot \mathrm{km})$

$R_{S}$

Resistance of the solution $\left(\mathrm{k} \Omega \cdot \mathrm{cm}^{2}\right.$ or $\left.\mathrm{k} \Omega\right)$

$R_{f}$

Membrane resistance $\left(\mathrm{k} \Omega \cdot \mathrm{cm}^{2}\right.$ or $\left.\mathrm{k} \Omega\right)$

$R_{c t}$

Charge transfer resistance of the steel $\left(\mathrm{k} \Omega \cdot \mathrm{cm}^{2}\right.$ or $\left.\mathrm{k} \Omega\right)$

$R_{p}$

Linear polarization resistance $\left(\mathrm{k} \Omega \cdot \mathrm{cm}^{2}\right.$ or $\left.\mathrm{k} \Omega\right)$

$\theta$

Phase shift (radian)

\section{Introduction}

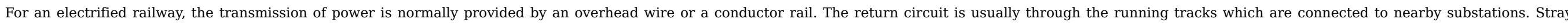

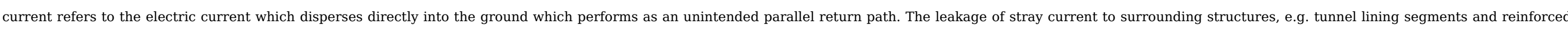

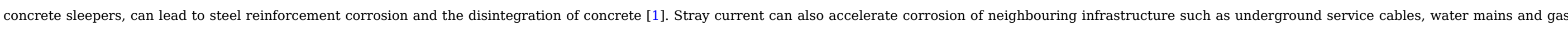

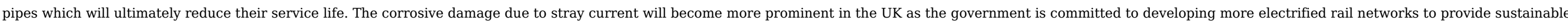

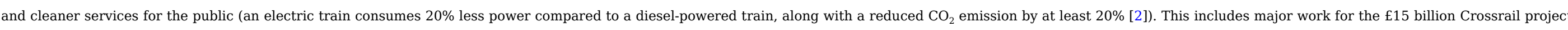




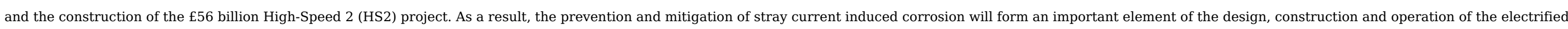

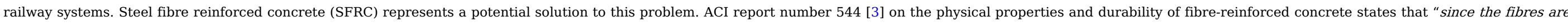

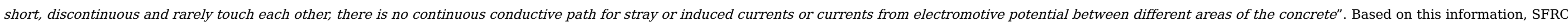

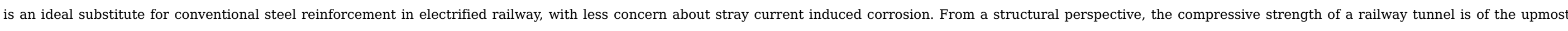

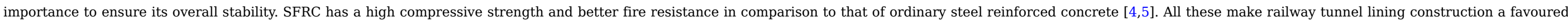

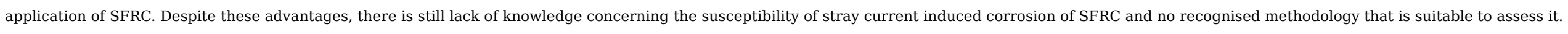

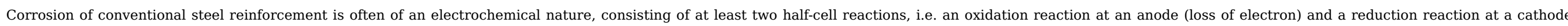

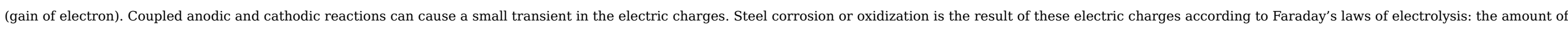

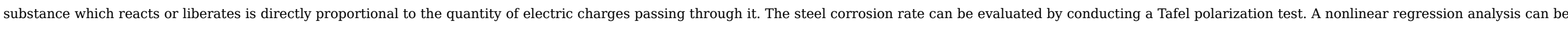
conducted to determine $I_{\text {corr }}$ based on Butler-Volmer equation (Eq. (1)).

$$
I=I_{\text {corr }}\left[\exp \left(\frac{\mathrm{E}-E_{\text {corr }}}{\beta_{a}}\right)-\exp \left(-\frac{\mathrm{E}-E_{\text {corr }}}{\beta_{c}}\right)\right]
$$

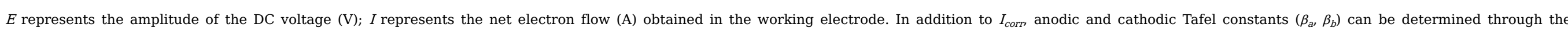

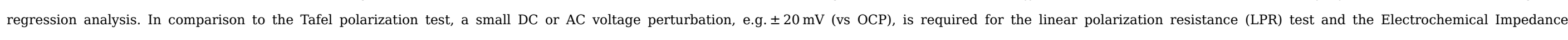
Spectroscopy (EIS) test. On the other hand, important kinetic parameters such as $\beta_{a}$ and $\beta_{b}$ cannot be determined through either LPR or EIS test due to the small range of voltage perturbation applied.

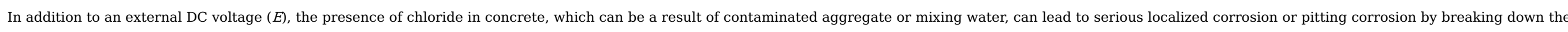

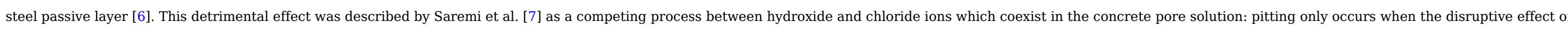

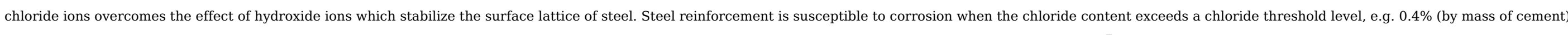

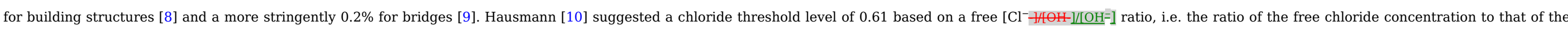

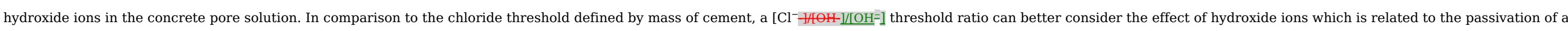
steel reinforcement.

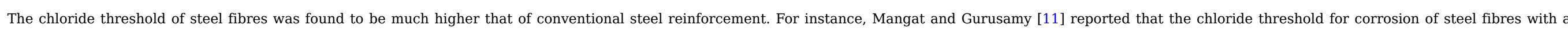

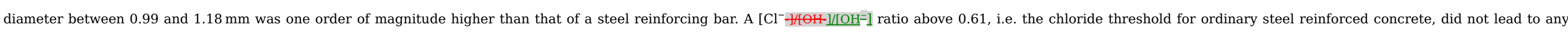

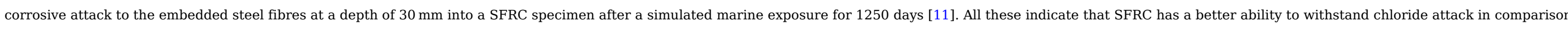

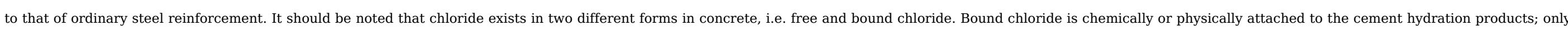

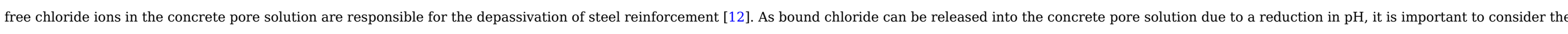
effect of $\mathrm{pH}$ when determining the chloride threshold for the corrosion of steel reinforcement $[8,13]$.

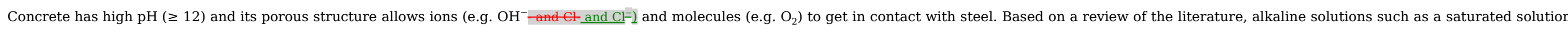

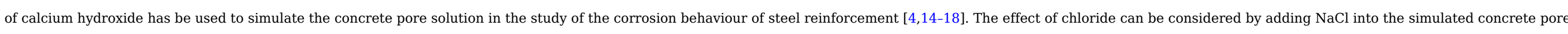

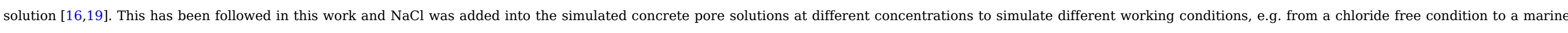

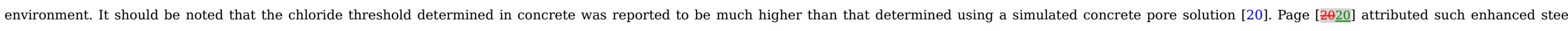

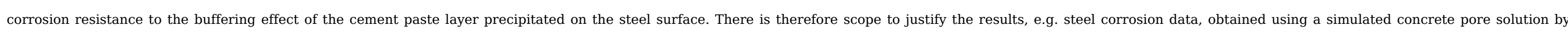
conducting a comparison study using a solid electrolyte such as concrete.

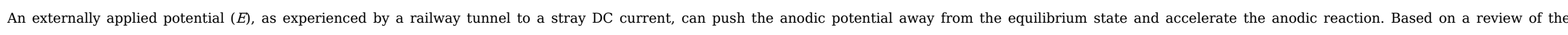

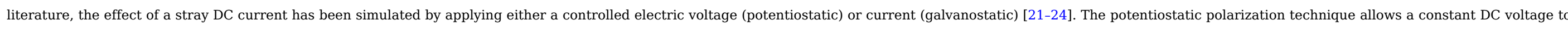

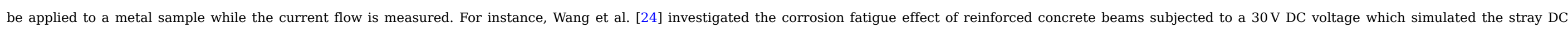




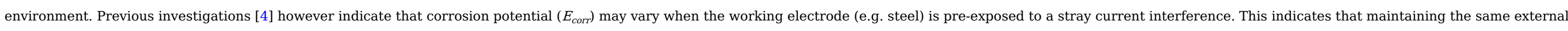

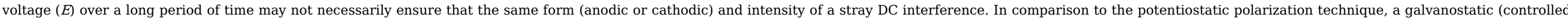

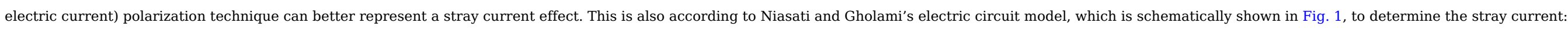

$i_{S}=\frac{R_{R} i_{T}}{R_{T}+R_{R}+R_{\text {soil }}}$

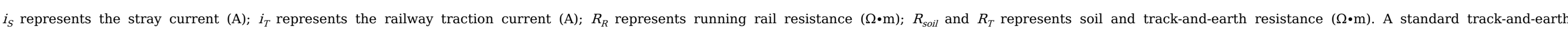

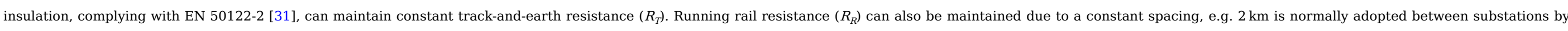

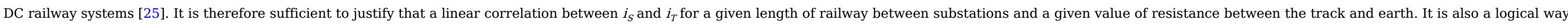

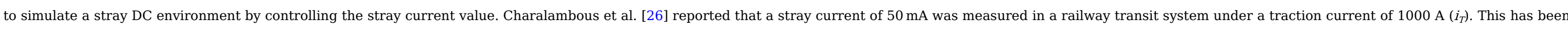
followed in this work and a constant DC current up to $50 \mathrm{~mA}$ was used to simulate the stray current arising from an electrified railway. This is detailed in Section 2.2 .

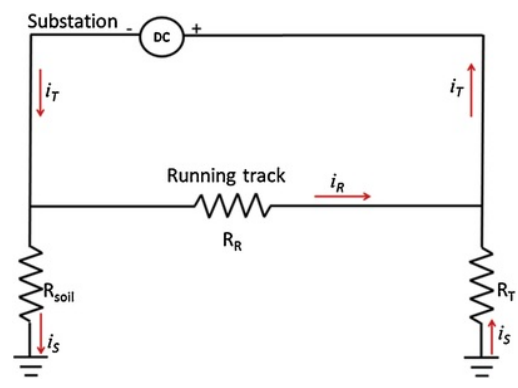

Fig. 1 Equivalent electronic circuit modelling the formation of stray current $\left(i_{S}\right)$.

alt-text: Fig. 1

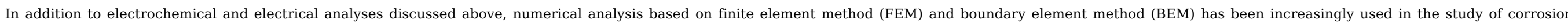

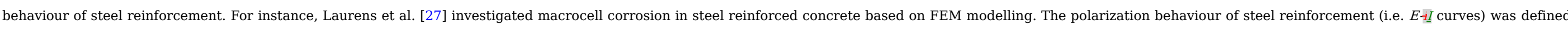

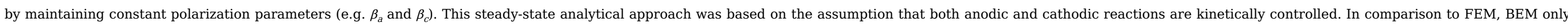

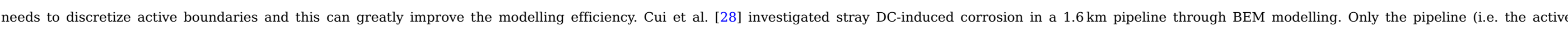

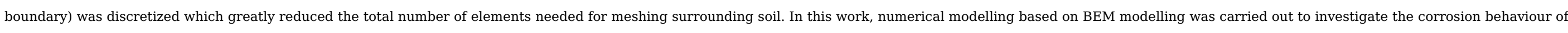
SFRC subjected to a simulated stray DC interference. This is discussed in Section 2.3.

\section{Experimental and analytical procedures}

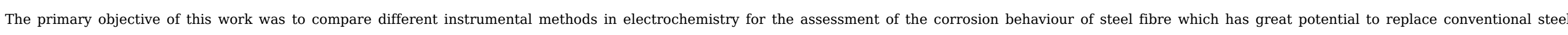

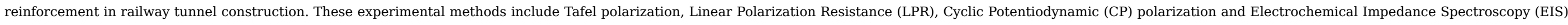

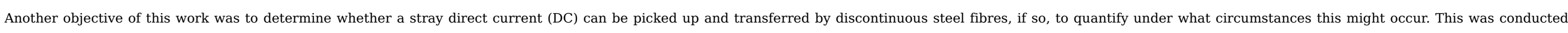
through the stray DC interference test as discussed in Section 2.2 and BEM modelling as discussed in Section 2.3.

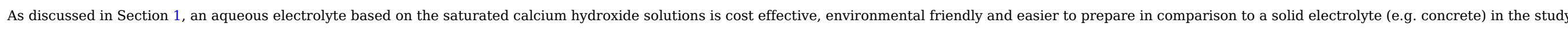

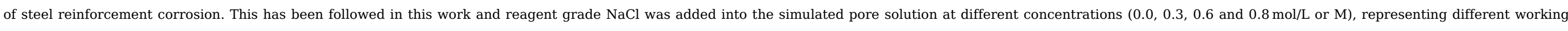

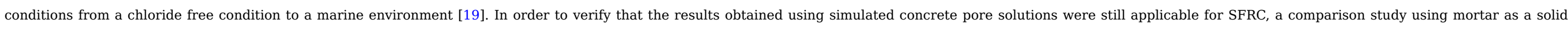
electrolyte was conducted and this is discussed in Section 2.2.2.

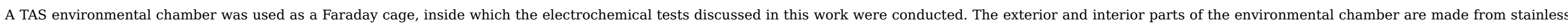




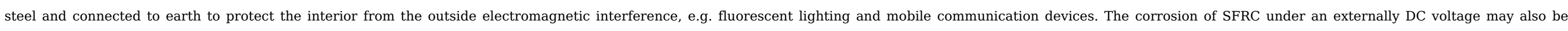

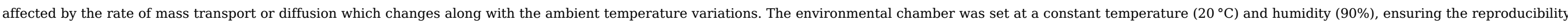
and repeatability of the experimental results.

\subsection{Corrosion behaviours of steel fibres}

\subsubsection{Tafel polarization test}

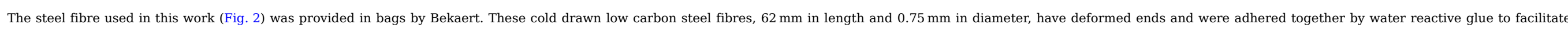

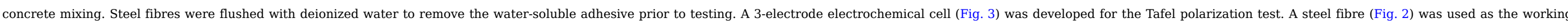

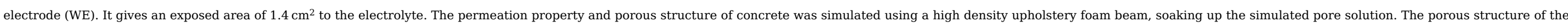

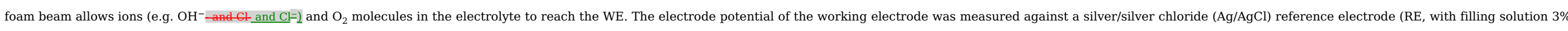

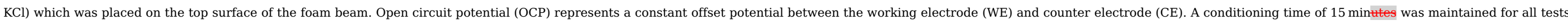

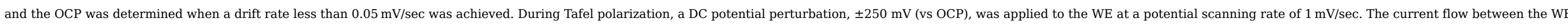

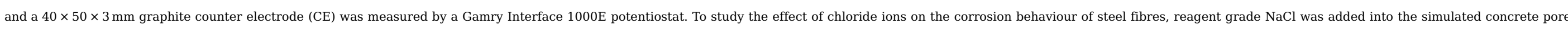

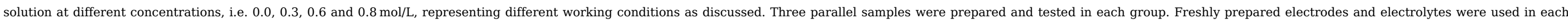
test. Tafel polarization results are discussed in Section 3.1.1.

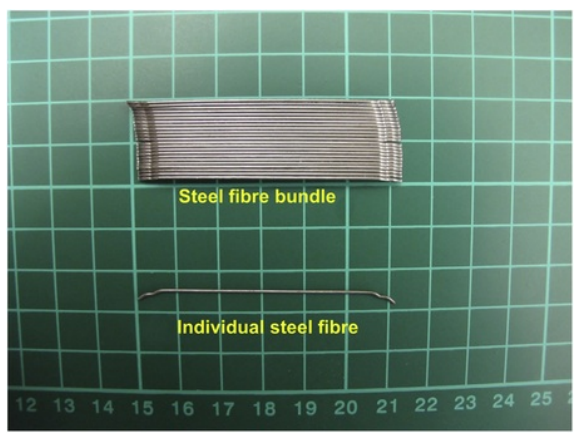

Fig. 2 Steel fibre (DRAMIX 4D 80/60BG).

alt-text: Fig. 2

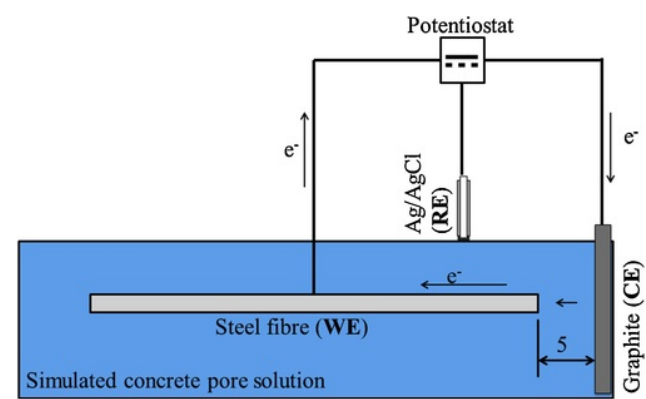

Fig. 3 Tafel polarization test (all units in $\mathrm{mm}$ ).

alt-text: Fig. 3

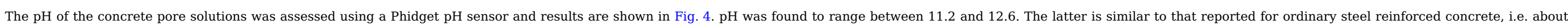




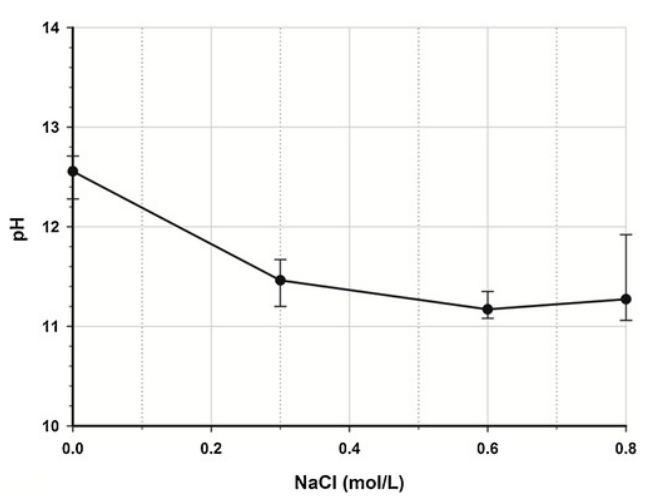

Fig. $4 \mathrm{pH}$ of simulated concrete pore solutions.

\section{alt-text: Fig. 4}

\subsubsection{Linear polarization resistance (LPR) test}

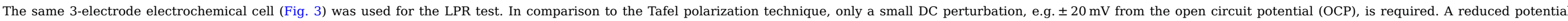

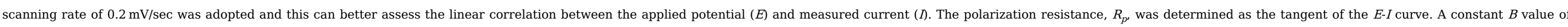

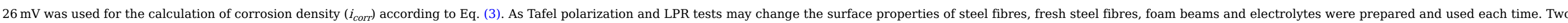
parallel samples were prepared and tested in each group.

$I_{\text {corr }}=\frac{B}{R_{p}}$

\subsubsection{Electrochemical impedance spectroscopy (EIS)}

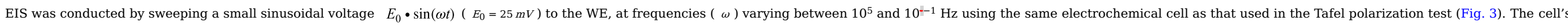

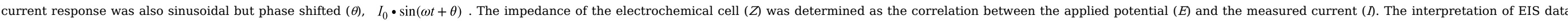

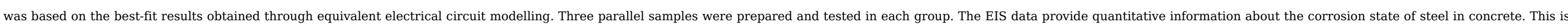
discussed in Section 3.1.3

\subsubsection{Cyclic Ppotentiodynamic (CP) polarization test}

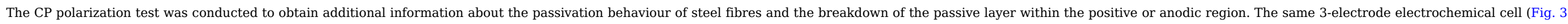

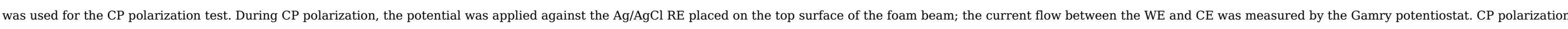

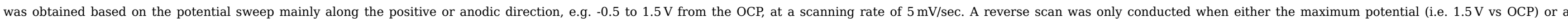

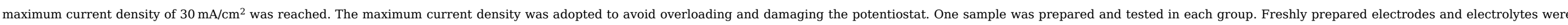

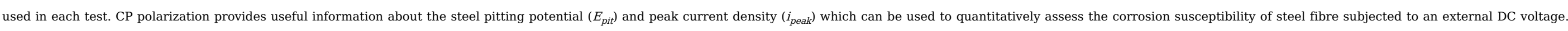
This is discussed in Section 3.1.4.

\subsection{Investigation of stray DC-induced corrosion in SFRC subjected to a simulated stray current interference}

\subsubsection{Stray DC interference test - use of simulated concrete pore solutions}




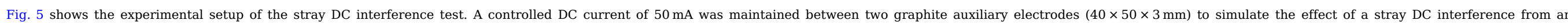

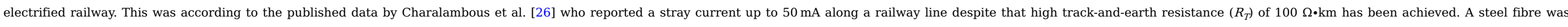

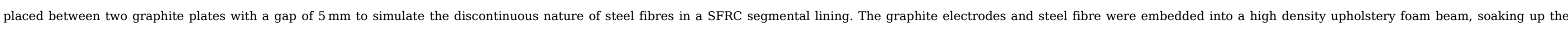

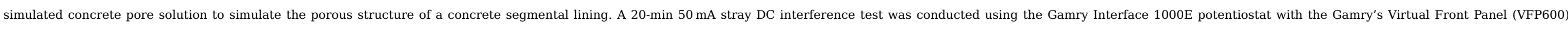

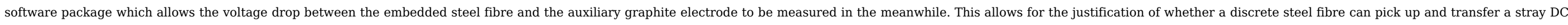

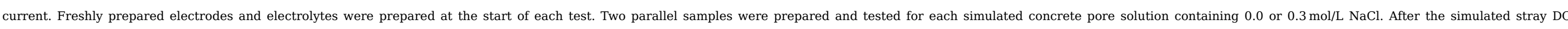

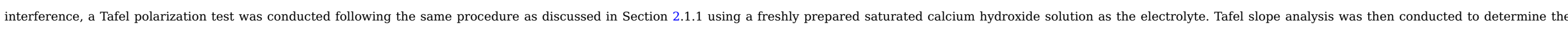
corrosion current density $\left(i_{\text {corr }}\right)$ and corrosion potential $\left(E_{\text {corr }}\right)$. Results are discussed in Section 3.2.1.

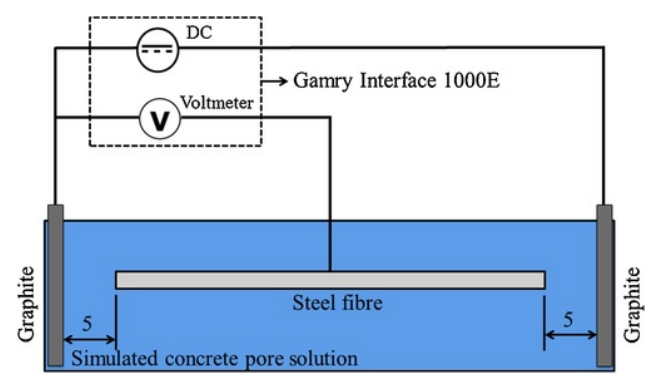

Fig. 5 Stray DC interference test (20-min $50 \mathrm{~mA})$.

alt-text: Fig. 5

\subsubsection{Stray DC interference test - corrosion measurement in SFRC}

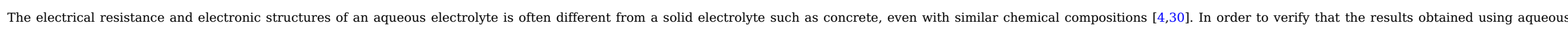

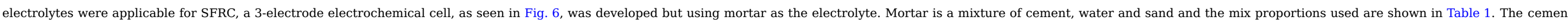

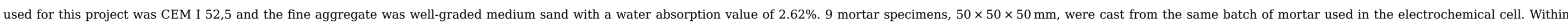

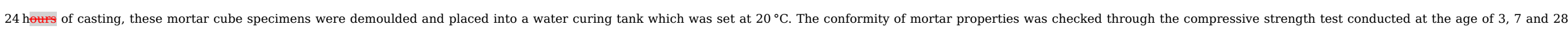
days after casting. Fig. 7 shows that a very consistent compressive strength has been achieved at different ages, indicating a good quality control during the casting and curing processes.

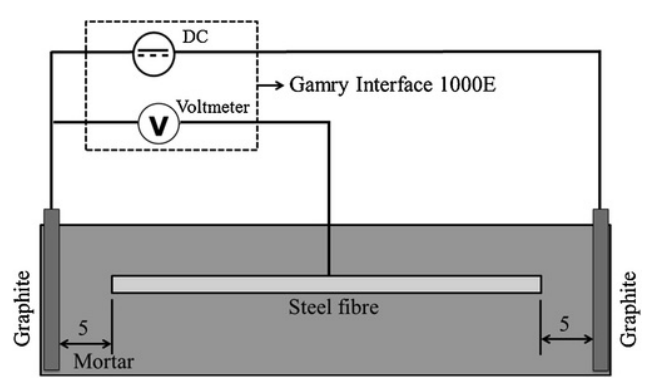

Fig. 6 Stray DC interference test (1-hr $30 \mathrm{~mA})$.

alt-text: Fig. 6

Table 1 Mortar mix proportions.

alt-text: Table 1 


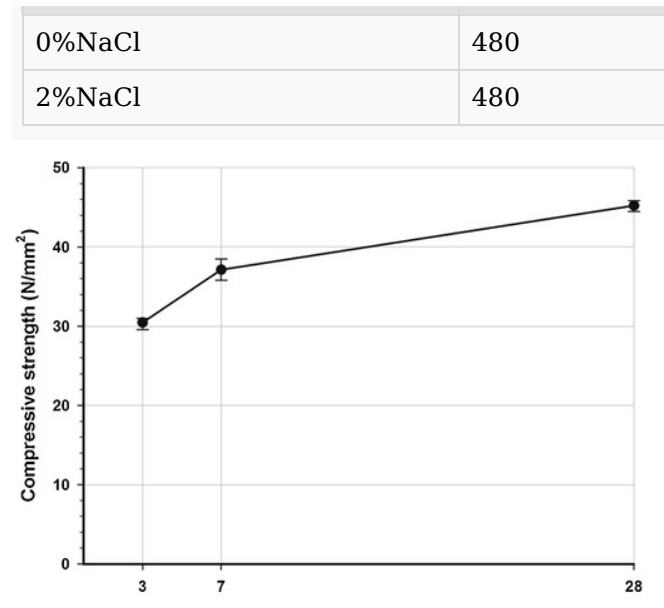

Time (days)

Fig. 7 Mortar compressive strength at the age of 3, 7 and 28 days (verification of conformity).

\section{alt-text: Fig. 7}

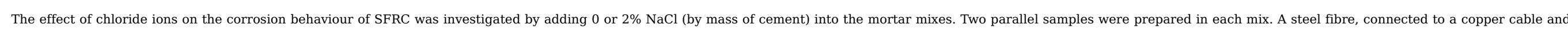

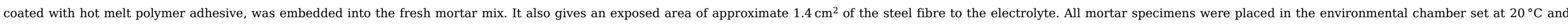

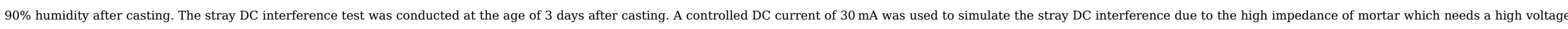

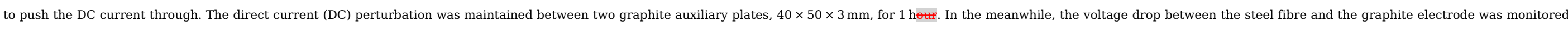

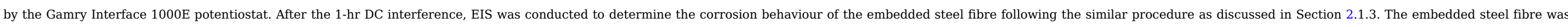

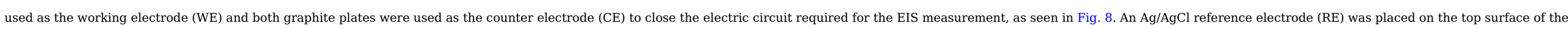

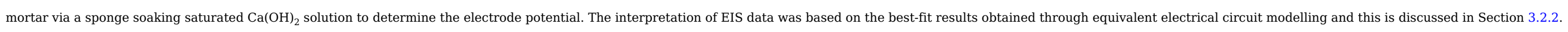

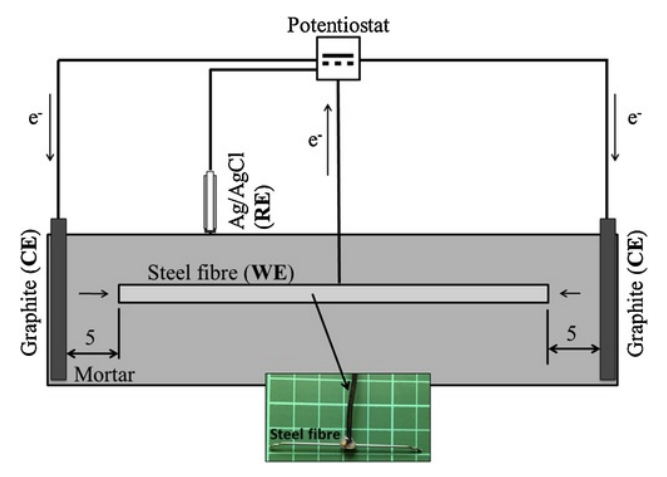

Fig. 8 SFRC EIS test.

\section{alt-text: Fig. 8}

\subsection{Boundary element method (BEM) modelling}

The developed electric potential $(E)$ in an energy conserved system is governed by Laplace equation (Eq. (4)) 


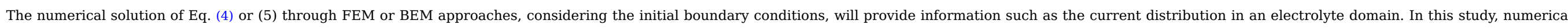

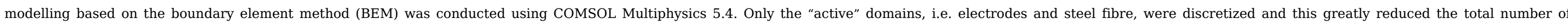

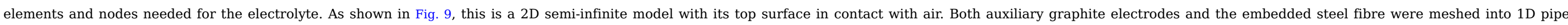

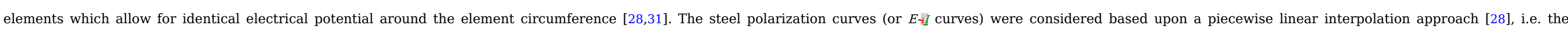

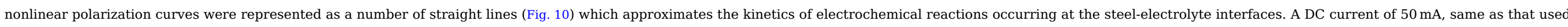

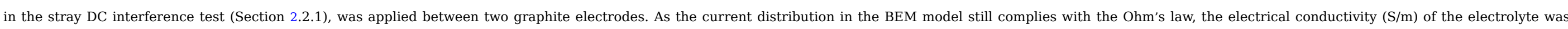

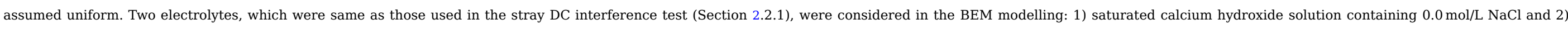

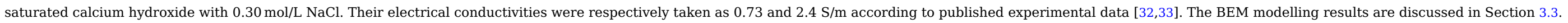

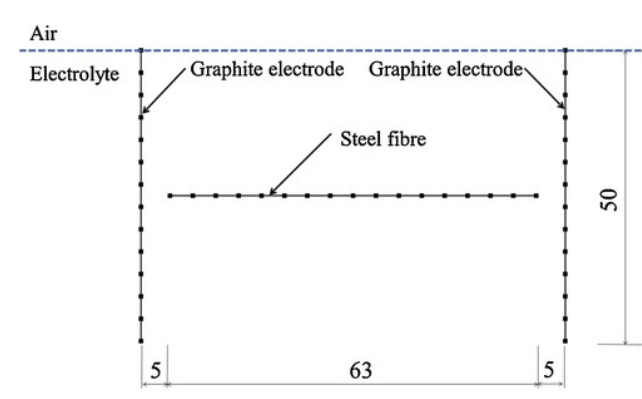

Fig. 9 BEM model (all units in $\mathrm{mm}$ ).

alt-text: Fig. 9

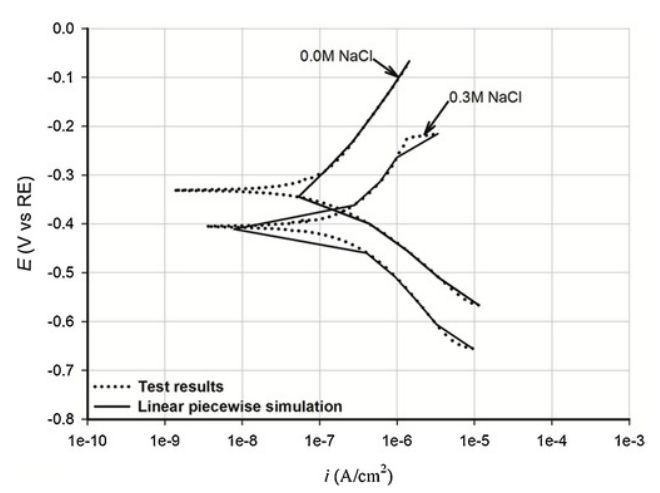

Fig. 10 Linear piecewise simulation of polarization (E- E-1) curves in BEM modelling

\section{alt-text: Fig. 10}

\section{Results and discussion}

3.1 Corrosion behaviour of steel fibres

\subsubsection{Tafel polarization results}




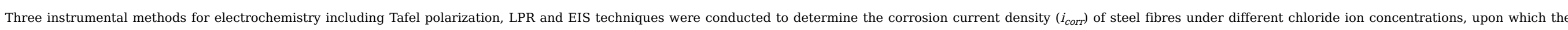

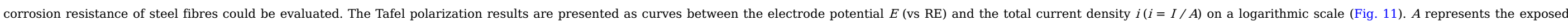

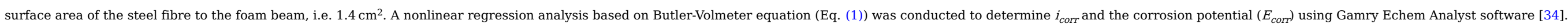

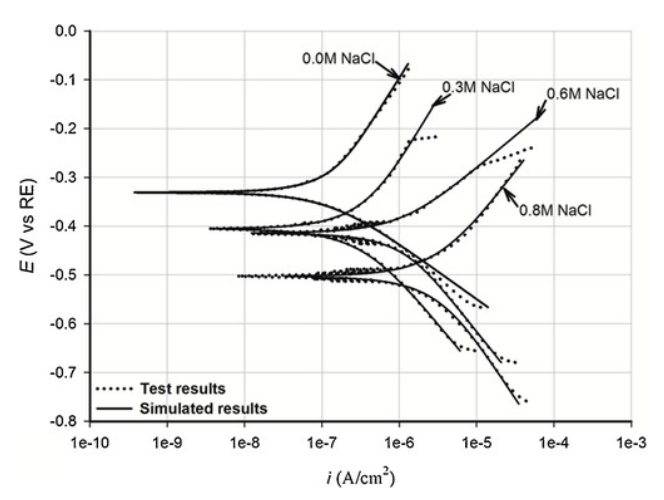

Fig. 11 Tafel polarization results (before pre-exposure to a DC current)

alt-text: Fig. 11

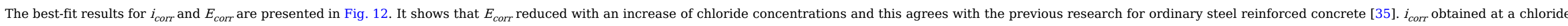

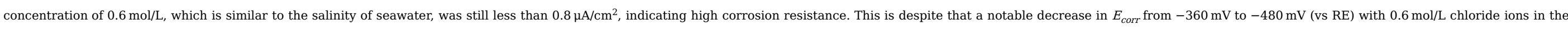
electrolyte. As the corrosion rate $(C R)$ is proportional to $i_{\text {corr }}$ an assessment for the corrosion severity based on $E_{\text {corr }}$ values only may lead to a biased result.

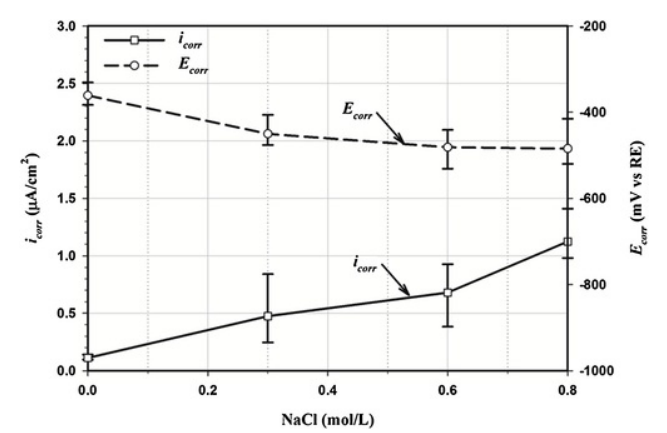

Fig. 12 Tafel polarization results (icorr and $E_{\text {corr }}$ ).

alt-text: Fig. 12

\subsubsection{LPR results}

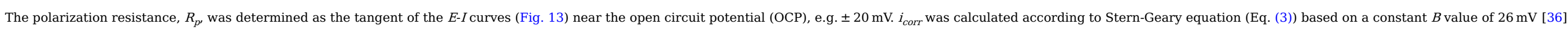

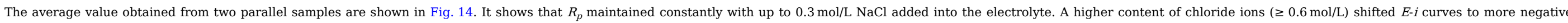

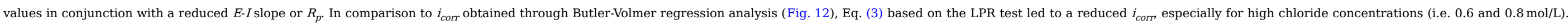
Stern-Geary equation (Eq. (3)) is a mathematically reduced form of Butler-Volmeter equation (Eq. (1)) with a constant $B$ value representing the effect of Tafel coefficients $\beta_{a}$ and $\beta_{c}$ [37]:

$B=\frac{\beta_{a} \beta_{c}}{\beta_{a}+\beta_{c}}$ 


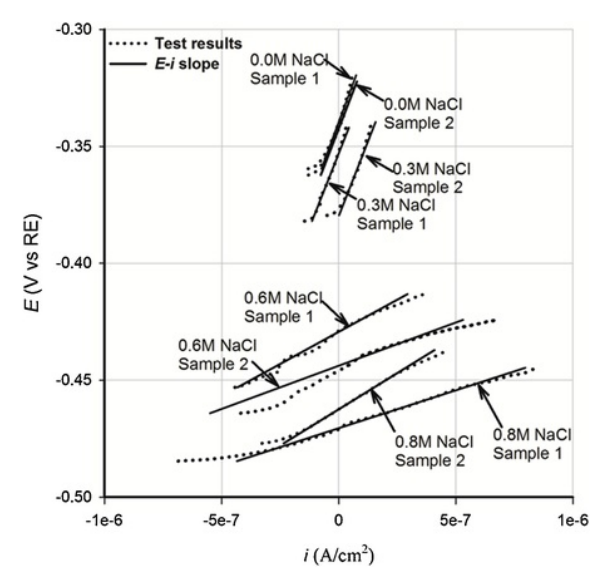

Fig. 13 LPR test results (before pre-exposure to a DC current).

\section{alt-text: Fig. 13}

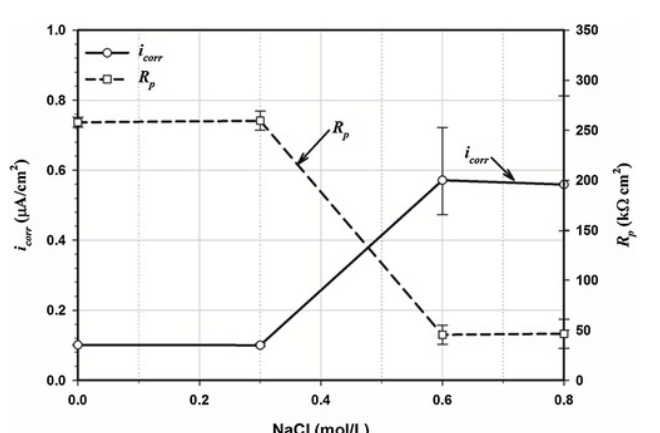

Fig. $14 i_{\text {corr }}$ determined based on LPR results.

$$
\text { (2) }
$$

(1)

(e) Nyctiot

\section{alt-text: Fig. 14}

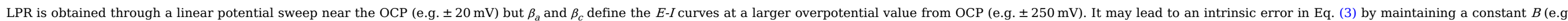
$26 \mathrm{mV}$ ) value when calculating $i_{\text {corr }}$ This is an area where ongoing research is undertaken.

\subsubsection{EIS results}

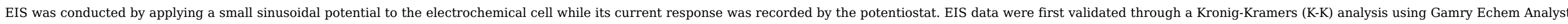

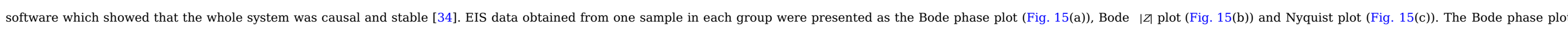

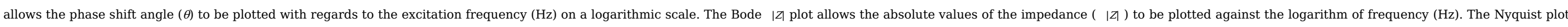

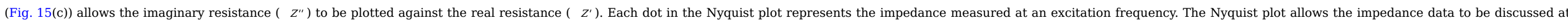
high and low frequencies: the transfer resistance dominates at high frequencies and diffusion or mass transfer determines at low frequencies [38]. The correlations between $|Z|, Z^{\prime}, Z^{\prime \prime}$ and $\theta$ are defined by Eq. (7) and (8).

$|Z|=\sqrt{\left(Z^{\prime}\right)^{2}+\left(Z^{\prime \prime}\right)^{2}}$ 


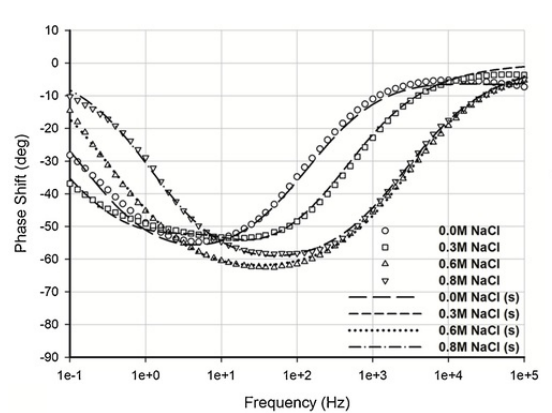

(a) Bode phase pla

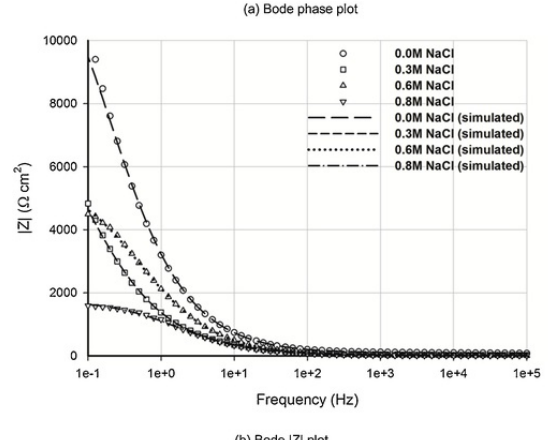

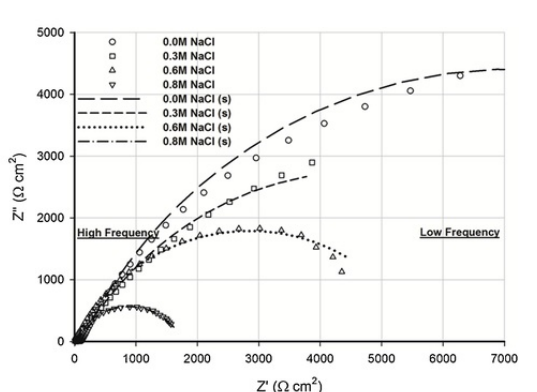

(c) Nyuust plot

Fig. 15 EIS data and best fit curves results (before pre-exposure to a DC current),

\section{alt-text: Fig. 15}

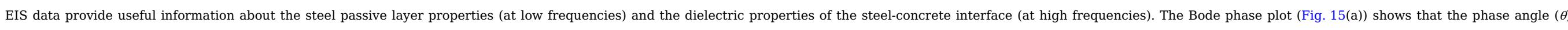

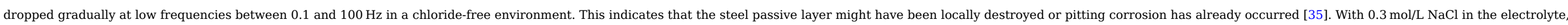

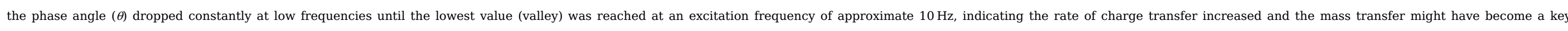

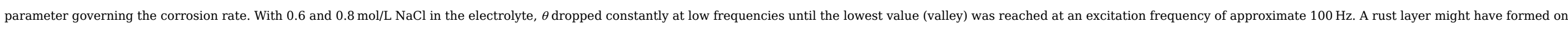
the steel fibre surface and the speed of the corrosion reactions was governed by the diffusion speed through the rust layer in such circumstances [35].

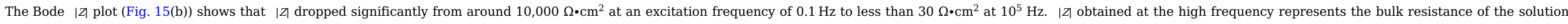

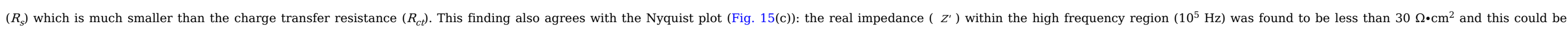
attributed to the small resistance of the aqueous electrolyte used.

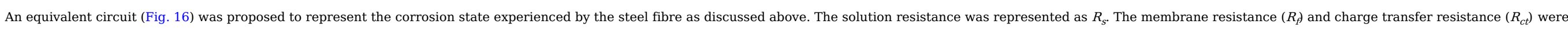

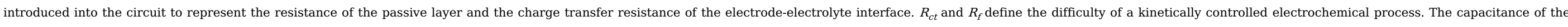

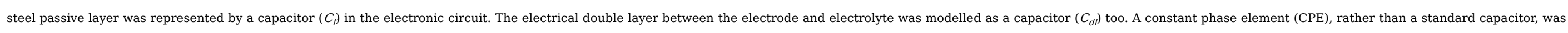
used in the equivalent circuits to model $C_{f}$ and $C_{d l}$ as it can better model the surface roughness and heterogeneousness of a double layer [14]. The impedance of a CPE can be defined as:

$Z(\omega)=\frac{1}{Q}(j \omega)^{-n}$ 


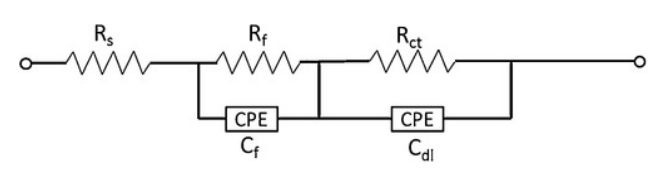

Fig. 16 Equivalent circuit model.

\section{alt-text: Fig. 16}

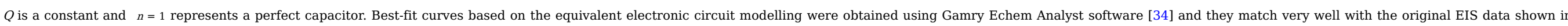

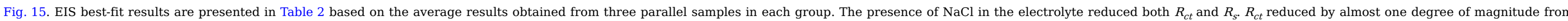

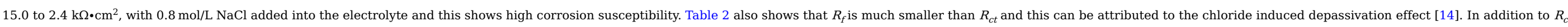

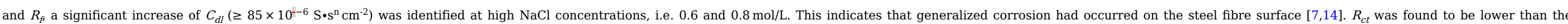

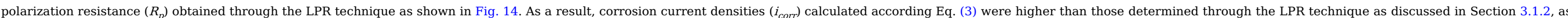

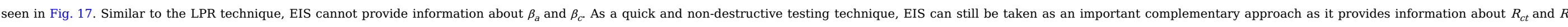
which define the difficulty of kinetically controlled corrosion reactions.

Table 2 EIS best-fit results (before pre-exposure to a DC current).

alt-text: Table 2

\begin{tabular}{|c|c|c|c|c|c|c|c|c|}
\hline & $\left.R_{s} \cdot \bullet \mathrm{em} 2\right) \operatorname{Rf}(\bullet \mathrm{cm} 2) \in \mathrm{ff}\left(10-\left(\Omega \cdot \mathrm{cm}^{2}\right)\right.$ & $\underline{R}_{l}\left(\Omega \cdot \mathrm{cm}^{2}\right)$ & $\underline{C}_{\underline{\underline{1}}}\left(10^{=6}{ }^{-6} \cdot \mathrm{s}^{\mathrm{n}} \cdot \mathrm{cm}^{-2}\right)$ & $n_{f}$ & & $\mathrm{dl}\left(10 \underline{\left(\mathrm{k} \Omega \bullet \mathrm{cm}^{2}\right.}\right)$ & $\underline{C}_{\underline{d}}\left(10^{-6} \mathrm{~S} \cdot \mathrm{S}^{\mathrm{n}} \bullet \mathrm{cm}^{-2}\right)$ & $n_{d l}$ \\
\hline \multirow[t]{2}{*}{$-0.0 \mathrm{~mol} / \mathrm{L} \mathrm{NaCl}$} & \multirow[t]{2}{*}{2.9} & \multirow[t]{2}{*}{40.6} & \multirow[t]{2}{*}{0.3} & \multirow[t]{2}{*}{0.70} & \multirow[t]{2}{*}{15.0} & -1.8 & \multirow[t]{2}{*}{39.1} & \multirow[t]{2}{*}{0.78} \\
\hline & & & & & & +2.8 & & \\
\hline \multirow[t]{2}{*}{$0.3 \mathrm{~mol} / \mathrm{L} \mathrm{NaCl}$} & \multirow[t]{2}{*}{8.9} & \multirow[t]{2}{*}{47.1} & \multirow[t]{2}{*}{294.5} & \multirow[t]{2}{*}{0.41} & \multirow[t]{2}{*}{5.8} & --2.7 & \multirow[t]{2}{*}{81.0} & \multirow[t]{2}{*}{0.73} \\
\hline & & & & & & +3.4 & & \\
\hline \multirow[t]{2}{*}{$0.6 \mathrm{~mol} / \mathrm{L} \mathrm{NaCl}$} & \multirow[t]{2}{*}{7.4} & \multirow[t]{2}{*}{80.5} & \multirow[t]{2}{*}{547.0} & \multirow[t]{2}{*}{0.60} & \multirow[t]{2}{*}{4.8} & --1.2 & \multirow[t]{2}{*}{85.5} & \multirow[t]{2}{*}{0.70} \\
\hline & & & & & & +0.8 & & \\
\hline \multirow[t]{2}{*}{$0.8 \mathrm{~mol} / \mathrm{L} \mathrm{NaCl}$} & \multirow[t]{2}{*}{9.2} & \multirow[t]{2}{*}{88.4} & \multirow[t]{2}{*}{682.0} & \multirow[t]{2}{*}{0.52} & \multirow[t]{2}{*}{2.4} & -0.9 & \multirow[t]{2}{*}{127.1} & \multirow[t]{2}{*}{0.75} \\
\hline & & & & & & +1.5 & & \\
\hline
\end{tabular}

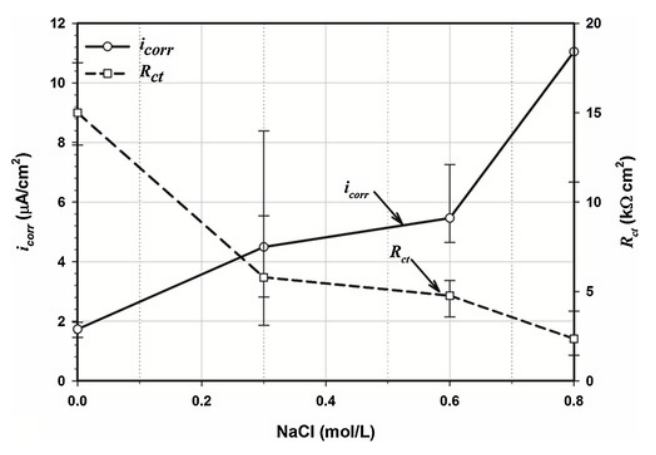

Fig. $17 i_{\text {corr }}$ determined based on EIS best-fit results. 


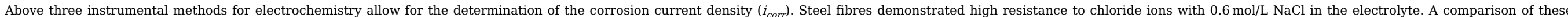

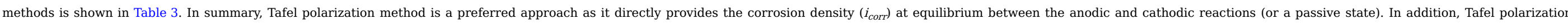

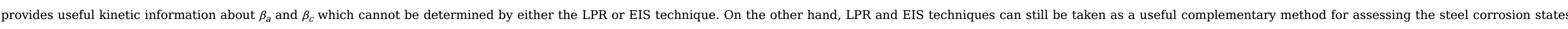
due to its high efficiency and non-destructive nature.

Table 3 Comparison of 3 methods for the determination of $i_{C o r r}$.

alt-text: Table 3

\begin{tabular}{|c|c|c|c|c|}
\hline & & Cost & Variation of $i_{\text {corr }}$ & Testing method \\
\hline & Apparatus cost & Experimental time & & \\
\hline Tafel polarization & High & $\leq 30$ minutes & Low & Destructive \\
\hline LPR & Low & $\leq 15$ minutes & High & Non-destructive \\
\hline EIS & High & $\leq 30$ minutes $^{*}$ & High & Non-destructive \\
\hline
\end{tabular}

${ }^{*}$ EIS scanning frequencies above $10^{--2} \mathrm{~Hz}$.

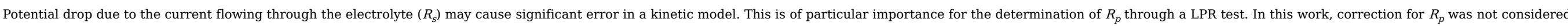
due to the strong aqueous electrolyte used and this assumption was verified by the EIS best-fit results as seen in Table 2: $R_{S}$ was less than $10 \Omega \bullet \mathrm{cm}^{2}$.

\subsubsection{CP polarization results}

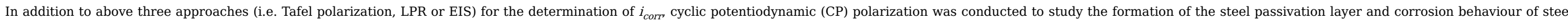

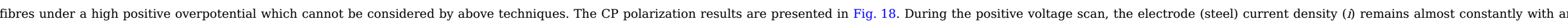

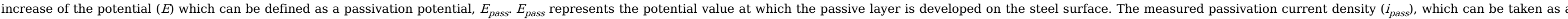

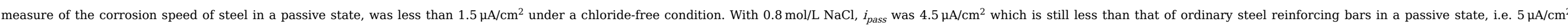
according to Edeleanu [39]. This result indicates that steel fibres have high corrosion resistance in a passive state, with and without NaCl in the electrolyte. 

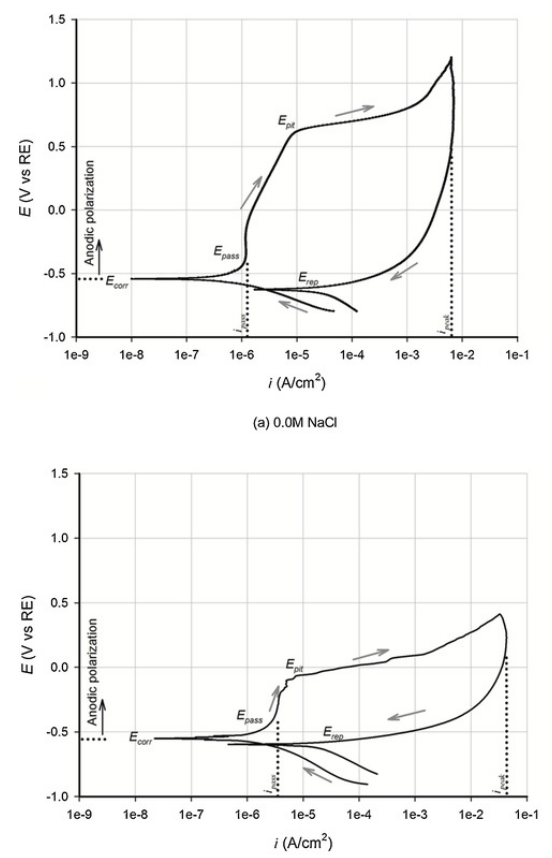

(b) $0.3 \mathrm{M} \mathrm{NaC}$

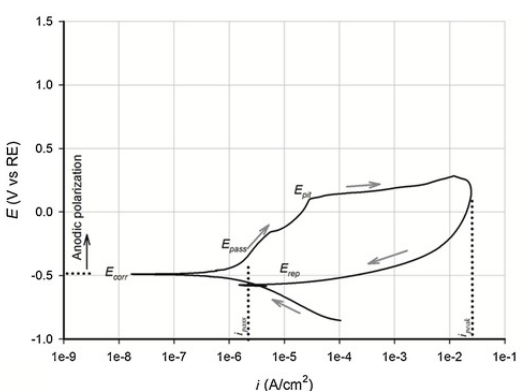

(c) $0.6 \mathrm{M} \mathrm{NaCl}$

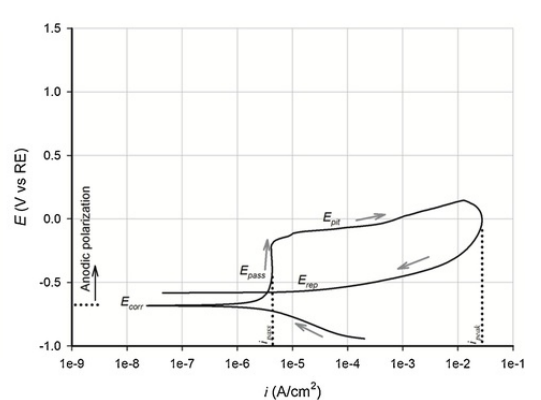

(d) $0.8 \mathrm{~m}$ Nac

Fig. $18 \mathrm{CP}$ polarization results (before pre-exposure to a DC current).

alt-text: Fig. 18

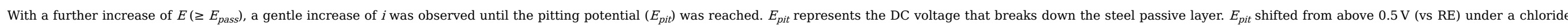

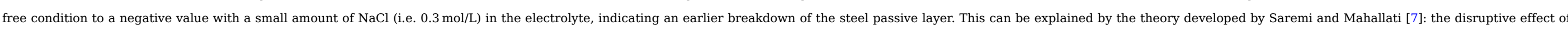
chloride ions overcame the stabilizing effect of hydroxide ions in the electrolyte.

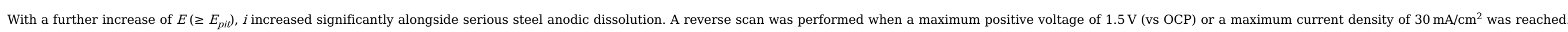

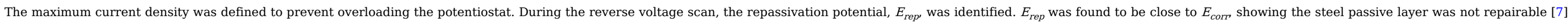

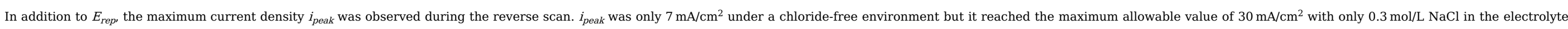

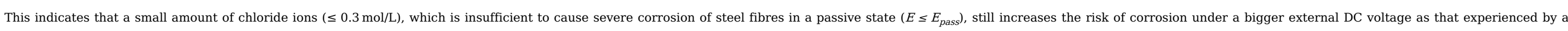

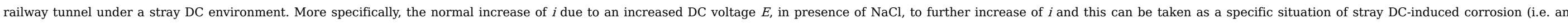

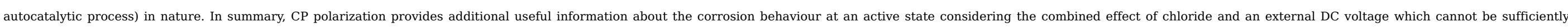
investigated through Tafel polarization, LPR or EIS.

\subsection{Corrosion behaviour of SFRC under a simulated stray DC environment}

\subsubsection{Corrosion behaviour of steel fibre in simulated concrete pore solutions}

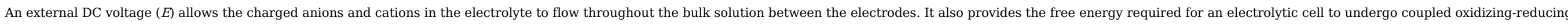

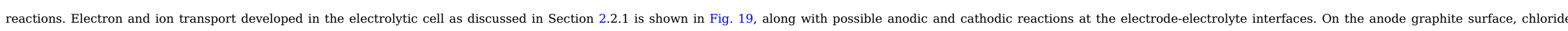

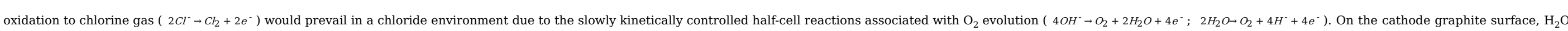




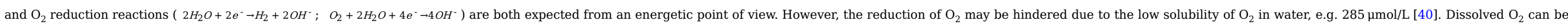
further reduced due to the other chemical compounds e.g. $\mathrm{NaCl}$ and $\mathrm{Ca}(\mathrm{OH})_{2}$, in the electrolyte [41].

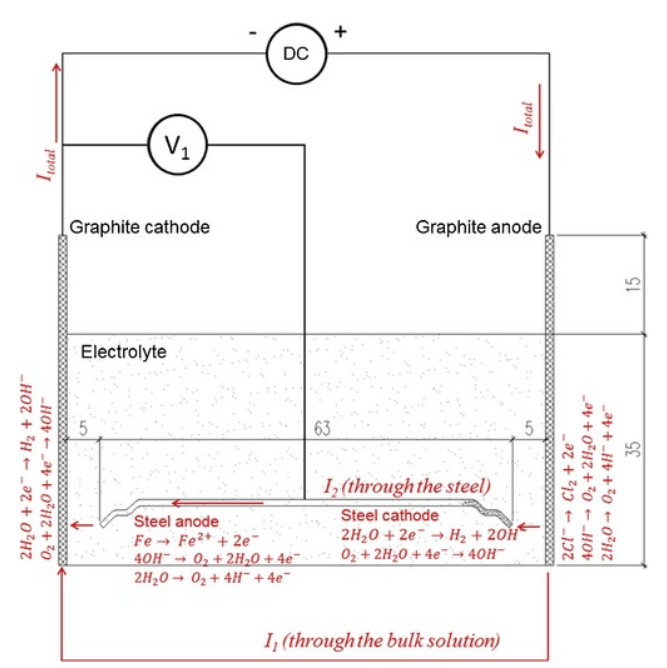

Fig. 19 Possible electrochemical reactions involved in the stray DC interference test.

\section{alt-text: Fig. 19}

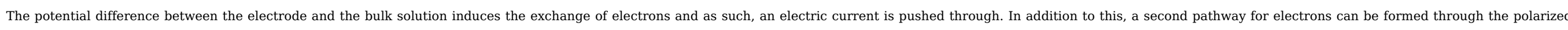

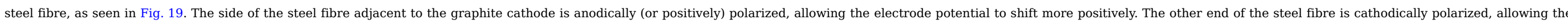

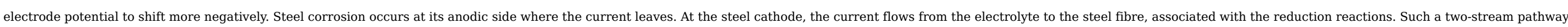

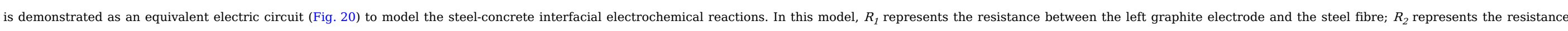

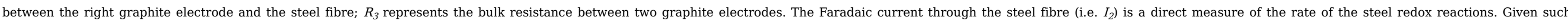
quantitative analysis, $I_{2}$ is a strong function of $R_{1}$ and it can be determined according to Ohm's law ( $I_{2}=\frac{V_{1}}{R_{1}}$ ).

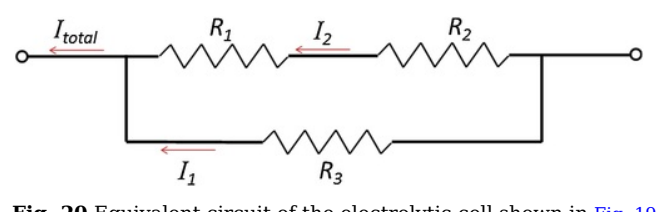

Fig. 20 Equivalent circuit of the electrolytic cell shown in Fig. 19.

alt-text: Fig. 20

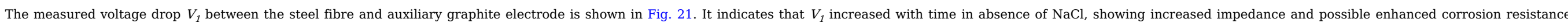

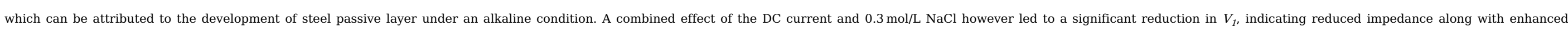
corrosion reactions. 


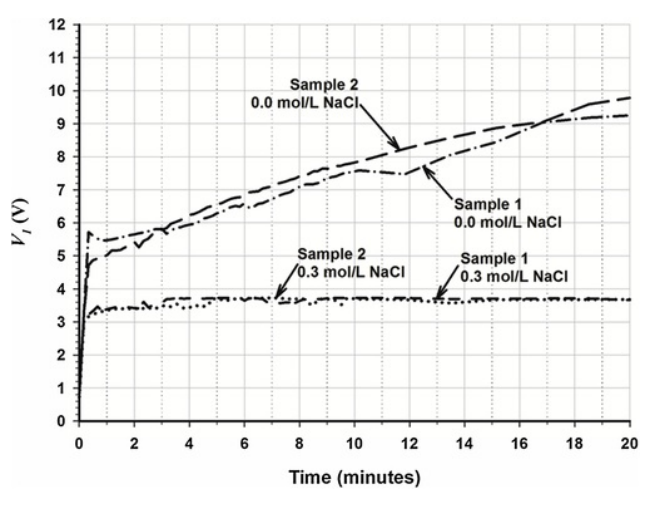

Fig. 21 Voltage drop between steel and graphite electrode $\left(V_{1}\right)$ - using simulated concrete pore solutions.

\section{alt-text: Fig. 21}

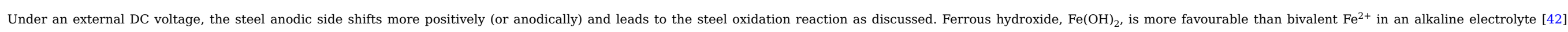

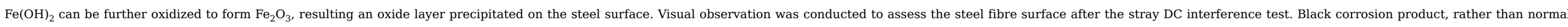

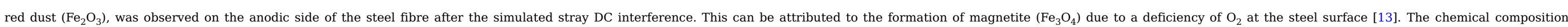
assessment of the corrosion product and its effects on the mechanical and durability performance of SFRC is an area where ongoing research is undertaken.

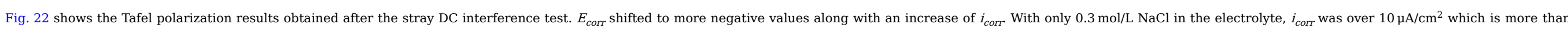

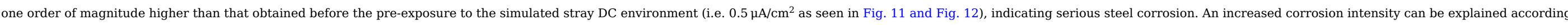

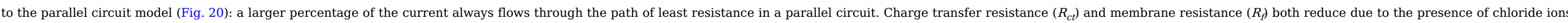

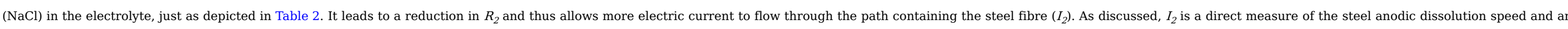

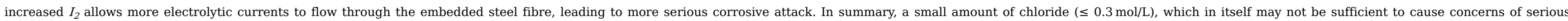
corrosion in SFRC, still increases the risk of stray DC induced corrosion.

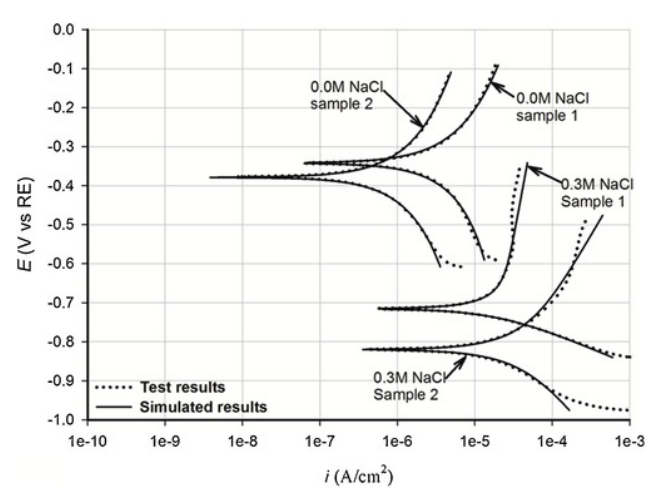

Fig. 22 Tafel polarization test results after the 30-m DC interference. alt-text: Fig. 22

\subsubsection{Effect of solid electrolyte on the corrosion behaviour of steel fibres under a simulated stray DC environment}

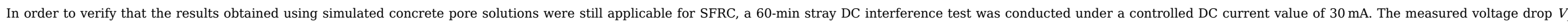

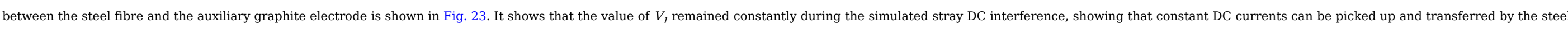




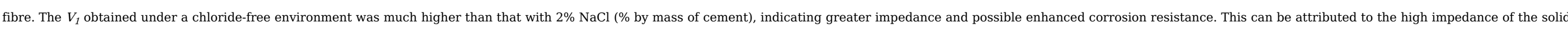

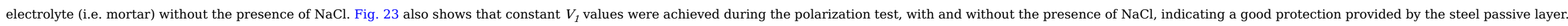

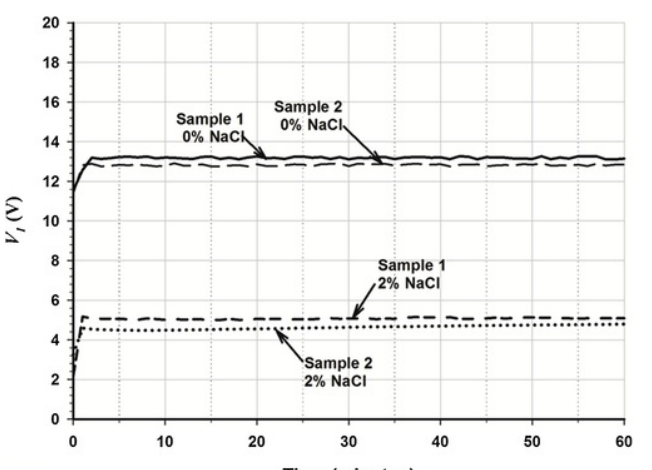

Fig. 23 Voltage drop between steel and graphite electrode $\left(V_{1}\right)$ - using SFRC as the solid electrolyte.

\section{(2) \\ (a) \\ (c) Nymot}

\section{alt-text: Fig. 23}

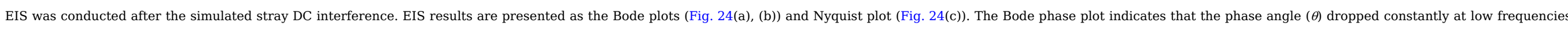

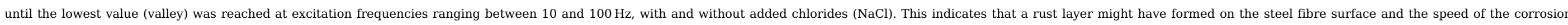

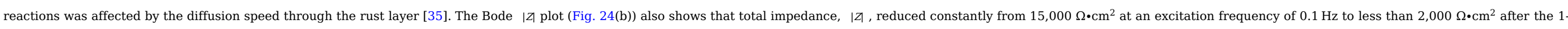

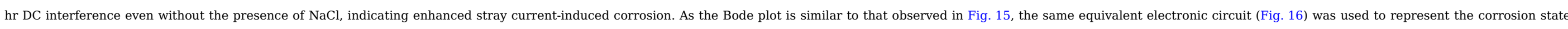

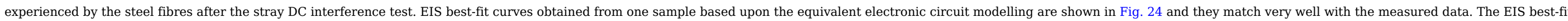

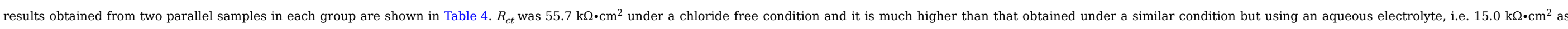

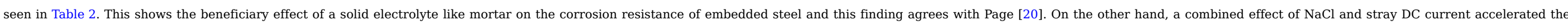

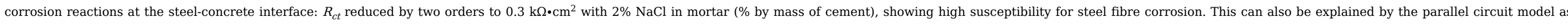

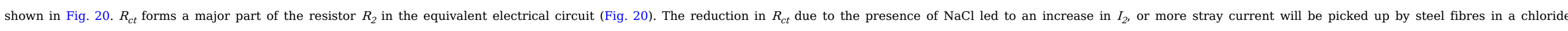

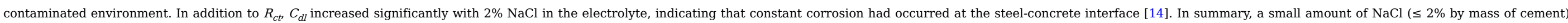
increases the risk of stray DC current induced corrosion. 

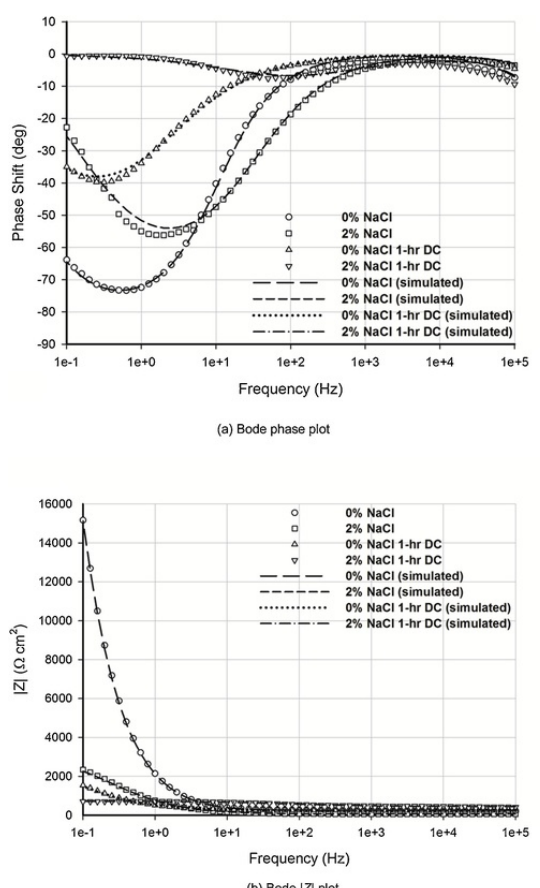

Fig. 24 EIS data - SFRC before and after stray DC interference.

alt-text: Fig. 24

Table 4 EIS best-fit results - SFRC before and after 1-hr stray DC interference.

alt-text: Table 4

\begin{tabular}{|c|c|c|c|c|c|c|c|}
\hline & $R_{s}(\cdot \bullet \mathrm{cm} 2) \mathrm{Rf}(\cdot \bullet \mathrm{cm} 2) \mathrm{Cf}\left(10-\left(\Omega \cdot \mathrm{cm}^{2}\right)\right.$ & $\underline{R}_{-}\left(\Omega \cdot \mathrm{cm}^{2}\right)$ & 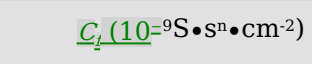 & $n_{f}$ & $R_{c t}\left(\mathrm{k} \cdot \mathrm{cm}^{2}\right) \mathrm{Cdl}\left(10-\left(\mathrm{k} \Omega \cdot \mathrm{cm}^{2}=\right)\right.$ & $\underline{C}_{\underline{d}}\left(10^{-6} \mathrm{~S} \cdot \mathrm{s}^{\mathrm{n}} \bullet \mathrm{cm}^{-2}\right)$ & $n_{d l}$ \\
\hline $0 \% \mathrm{NaCl} 0-\mathrm{hr}$ & 10 & 248.1 & 3.1 & 0.90 & $55.7 \pm 1.5$ & 92.9 & 0.93 \\
\hline $2 \% \mathrm{NaCl} 0-\mathrm{hr}$ & 7 & 59.2 & 1.4 & 0.99 & $3.1 \pm 0.2$ & 306.1 & 0.76 \\
\hline $0 \% \mathrm{NaCl} 1-\mathrm{hr}$ & 8 & 193.8 & 0.6 & 0.99 & $3.6 \pm 0.2$ & 803.2 & 0.66 \\
\hline $2 \% \mathrm{NaCl} 1-\mathrm{hr}$ & 6 & 443.5 & 0.4 & 0.99 & $0.3 \pm 0.2$ & 116.4 & 0.56 \\
\hline
\end{tabular}

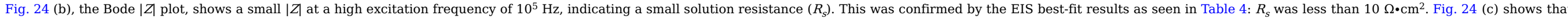

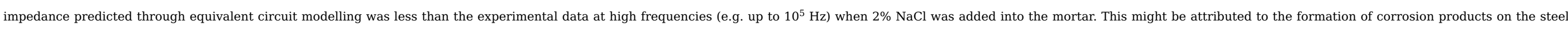
surface due to the combined effect of stray currents and NaCl. This is an area where ongoing research including scanning electron microscope (SEM) analysis is undertaken. Results will be discussed in a separate paper.

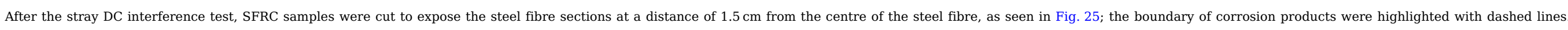

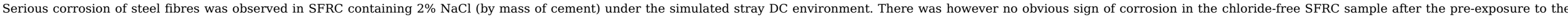
simulated stray DC interference, indicating the mitigation effect of the solid electrolyte (i.e. mortar) used. 


$$
\text { (a) } 0 \% \mathrm{NaCl}
$$

(b) $2 \% \mathrm{NaCl}$

Fig. 25 Section of SFRC after 1-hr stray DC interference.

$$
\text { (2) } 0.0 \text { a NaCl }
$$

(b) 0.3 NaCl

\section{alt-text: Fig. 25}

\subsection{BEM modelling of stray DC induced corrosion}

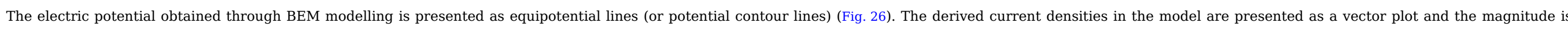

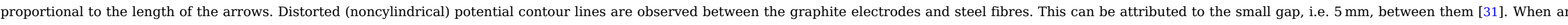

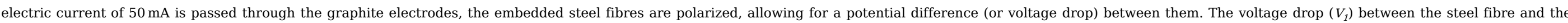

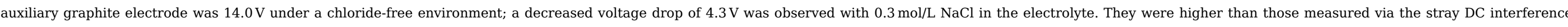

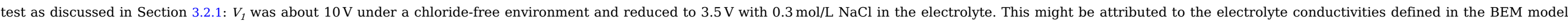
they represented the aqueous electrolytes [32,33] but they may not sufficiently address the different electrical conductivity of the high density upholstery foam used in the stray DC interference test. 


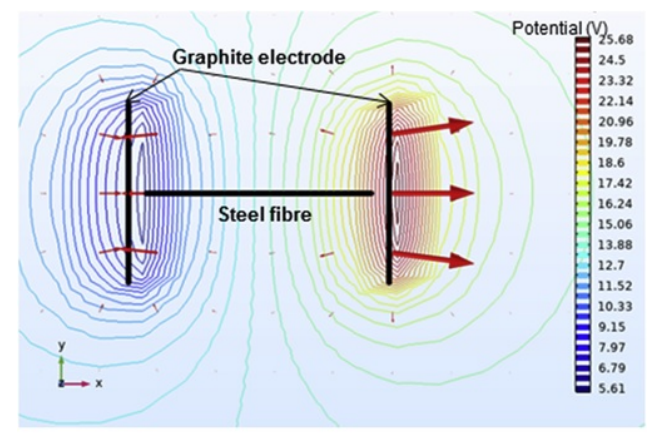

(a) $0.0 \mathrm{~mol} / \mathrm{L} \mathrm{NaCl}$

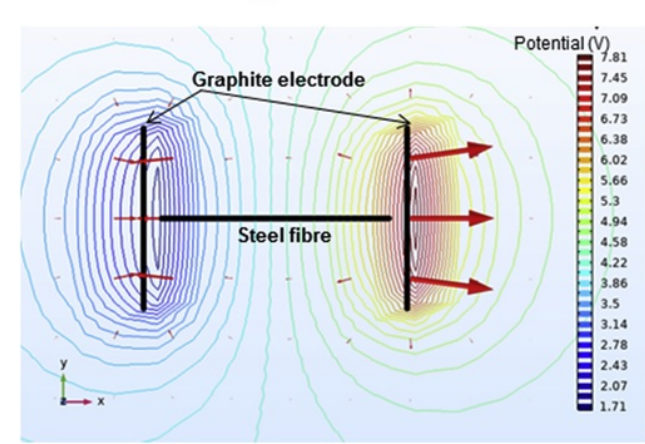

(b) $0.3 \mathrm{~mol} / \mathrm{L} \mathrm{NaCl}$

Fig. 26 BEM modelling result - equipotential lines and current density vectors.

\section{alt-text: Fig. 26}

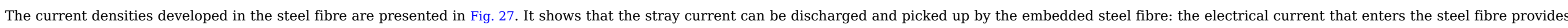

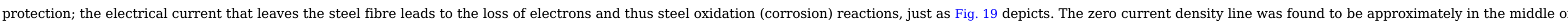

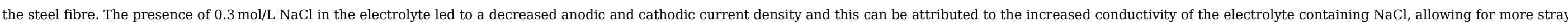

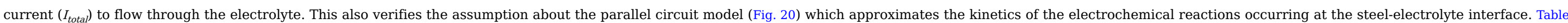

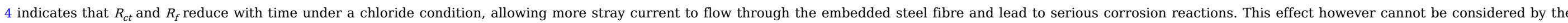

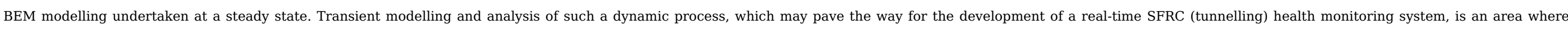
ongoing research is being conducted. 


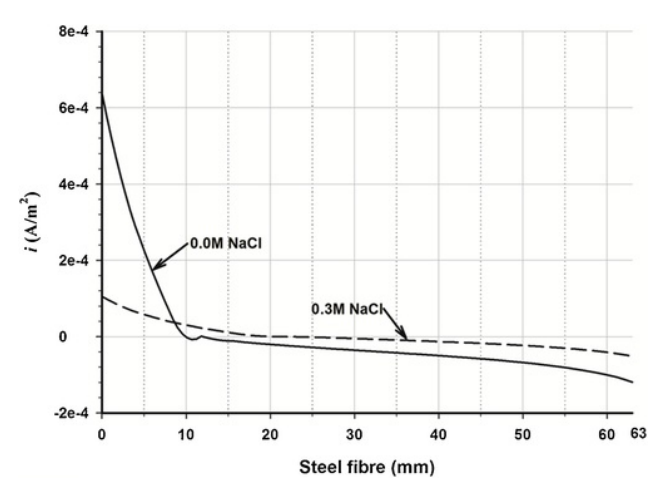

Fig. 27 BEM modelling result - steel fibre current densities.

\section{alt-text: Fig. 27}

\section{Conclusion}

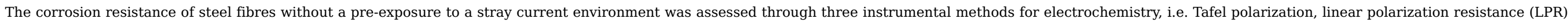

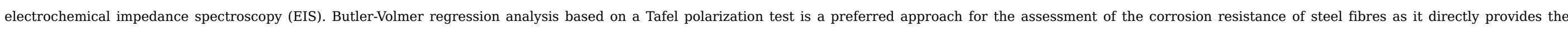
corrosion density $\left(i_{c o r r}\right)$ at equilibrium between the anodic and cathodic reactions. Steel fibre demonstrates high corrosion resistance even under a high chloride ion concentration condition (e.g. 0.6 mol/L).

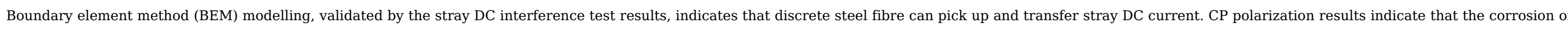

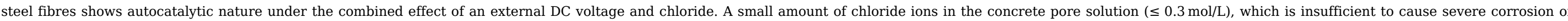

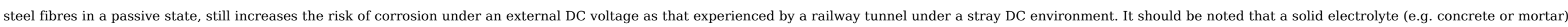

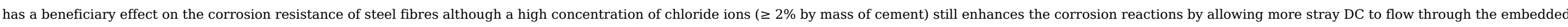
steel fibre.

\section{Acknowledgements}

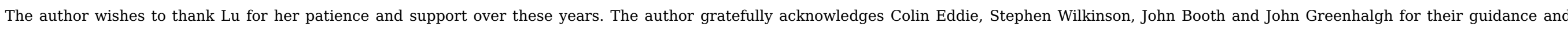
advice.

\section{References}

[1] L. Bertolini, M. Carsana and P. Pedeferri, Corrosion behaviour of steel in concrete in the presence of stray current, Corrosion Science. Sci. 49, 2007, 1056-1068.

[2] R. Kemp, Traction energy mEnergy Metrics, 2007, Rail Safety and Standards Board, Lancaster University; UK.

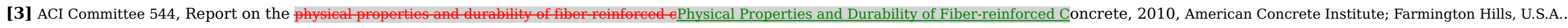

[4] K. Tang, Stray current induced corrosion to steel fibre reinforced concrete, Cemt Rester. 100, 2017, 445-456.

[5] K. Tang, Stray alternating current (AC) induced corrosion of steel fibre reinforced concrete, Corrosion Science. Sci. 152, 2019, $153-171$.

[6] A.M. Neville, Properties of $€$ Concrete, 2011, Pearson Education Limited; England.

[7] M. Saremi and E. Mahallati, A study on chloride-induced depassivation of mild steel in simulated concrete pore solution, Cement and Concrete Research. Concr. Res. 32, 2002, 1915-1921.

[8] BRE, Digest 444, Part 3 Corrosion of steel in concrete: investigation and aSteel in Concrete: Investigation and Assessment, 2000, BRE, Bracknell. 
[9] P. Vassie, Reinforcement corrosion and the durability of concrete bridges, Procedings of the Institum of Civil Enginers. Inst. Civ. Enq. 76, 1985, 1253-1256.

[10] D.A. Hausmann, Steel corrosion in concrete, Materials protection 6, 1967, 19-23.

[11] P.S. Mangat and K. Gurusamy, Corrosion resistance of steel fibres in concrete under marine exposure, Cement Concr. Res. 18, 1988 , 44-54.

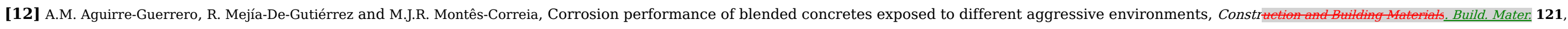
2016, 704-716.

[13] Concrete Society, Technical Report 44 Relevance of eracking in conerete to reinforeement eCracking in Concrete to Reinforcement Corrosion, 2015, Concrete Society; Surrey, UK.

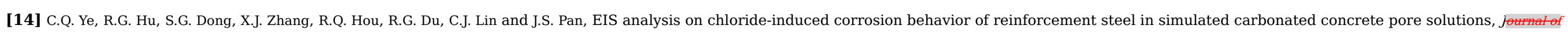
Electramalytical Chemistry. Electroanal. Chem. 688, 2013, 275-281.

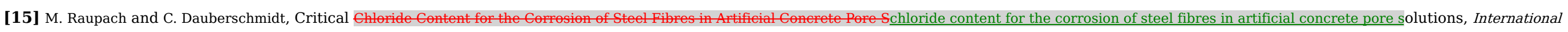
Concrete Abstracts Portal 212, 2003, 165-180.

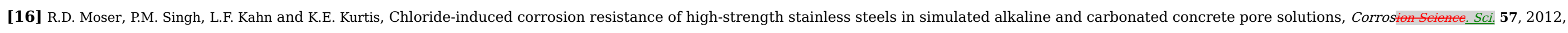
$241-253$.

[17] A. Poursaee, Corrosion of steel bars in saturated $\mathrm{Ca}(\mathrm{OH})_{2}$ and concrete pore solution, Concrete research letters 1, $2010,90-97$.

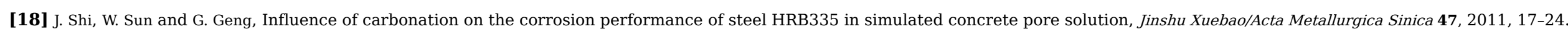

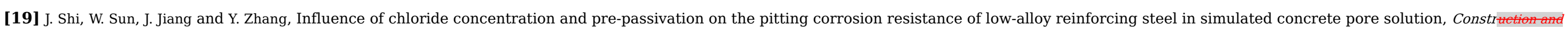
Building Materials. Build. Mater, 111, 2016, 805-813.

[20] C.L. Page, Initiation of chloride-induced corrosion of steel in concrete: Rrole of the interfacial zone, Materials and Corrosion. Corros. 60, 2009, 586-592.

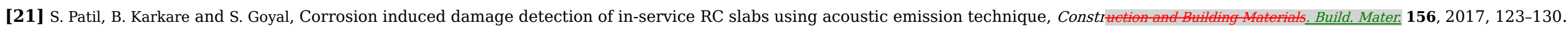

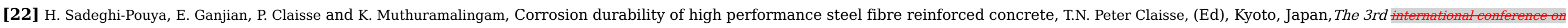

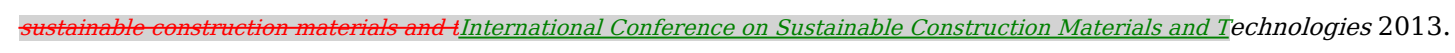

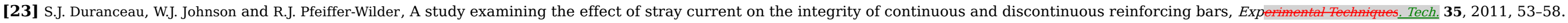

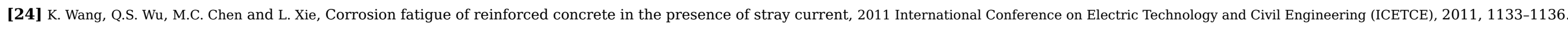

[25] A. Yadav, Traction choices: overhead ac vs third rail dc, International Railway Journal 2013.

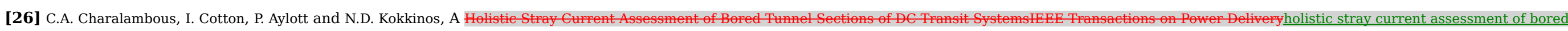
tunnel sections of DC transit systems, Ieee Trans. Power Deliv 28, 2013, 1048-1056.

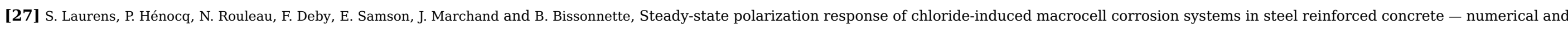
experimental investigations, Cemt Concr. Res. 79, 2016, 272-290.

[28] G. Cui, Z.-L. Li, C. Yang and M. Wang, The influence of DC stray current on pipeline corrosion, Petom Set. 13, 2016, 135-145.

[29] J. Wang, Analytical eElectrochemistry, 2000, Wiley-VCH; New York, USA.

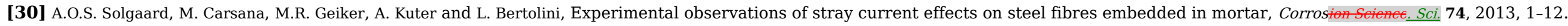




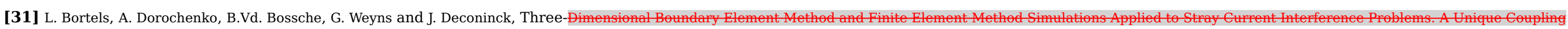

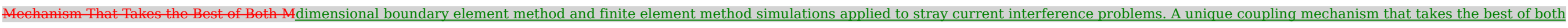
methods, Corrosion 63, 2007, 561-576.

[32] S. K and N. TA, Influence of mixing vehicle on dissociation of calcium hydroxide in solution, J. Endod. 26, 2000, 649-651.

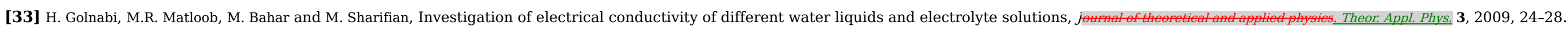

[34] Gamry, Gamry Echem Aechem analyst, Gamry Instruments, 2015, Inc..

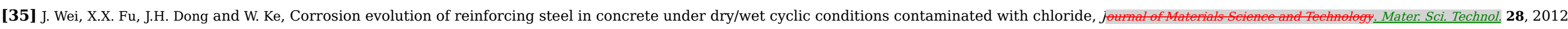
905-912.

[36] C. Andrade and C. Alonso, Corrosion rate monitoring in the laboratory and on-site, Constrentiond Building Materials. Build. Mater. 10, 1996, 315-328.

[37] M. Stern and A.L. Geary, Electrochemical polarization I. aA theoretical analysis of the shape of polarization curves, The Electrocheal Soeietelectrochem. Soc. Interface 104, 1957.

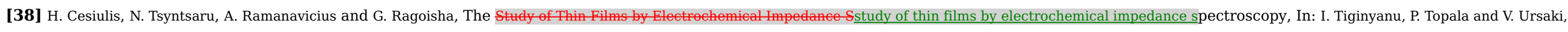
(Eds.), Nanostructures and Thin Films for Multifunctional Applications, 2016, Springer International Publishing.

[39] C. Edeleanu, Corrosion control by anodic protection, Platinum Metals Rev. 4, 1960, 86-91.

[40] P.R. Roberge, Corrosion engineering: principles and pEngineering: Principles and Practice, 2008, McGraw-Hill.

[41] B.V. Lenntech, Oxygen (O) and $\# \underline{W}$ ater, 2017.

[42] B. Popov, Corrosion engineering: principles and solved pEngineering: Principles and Solved Problems, 2015, Elsevier Science Ltd.

\section{Queries and Answers}

Query: Please check the presentation for the Tables 1-4, and correct if necessary.

Answer: All four tables (the contents in green) are correct.

Query: Please check that the affiliation link the author with correct departments, institutions, and locations, and correct if necessary.

Answer: The postcode should be UB8 3PH. This has been corrected in the context.

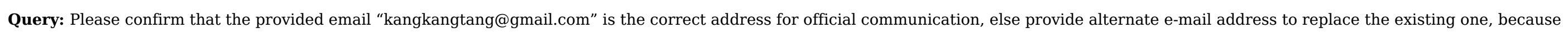
private e-mail address should not be used in articles as the address for communication.

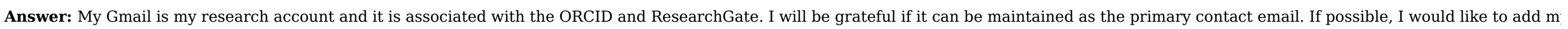
University email address (kangkang.tang@brunel.ac.uk) alongside my Gmail. Thank you!

Query: The author names have been tagged as given names and surnames (surnames are highlighted in teal color). Please confirm if they have been identified correctly.

Answer: Yes. My name is shown properly.

Query: Please check the country name added in the affiliation, and correct if necessary.

Answer: Yes. This is correct.

Query: Please check the presentation for all the equations, and correct if necessary. 
Answer: All equations have been checked and they are correct.

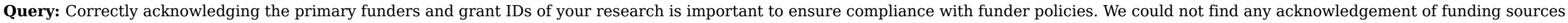
in your text. Is this correct?

Answer: This project is not funded.

Query: Please provide volume number/issue number/page range for the Ref. [25].

Answer: "International Railway Journal" is published online (railjournal.com). Please use Feb as the volume, i.e.

A. Yadav, Traction choices: overhead ac vs third rail dc, International Railway Journal. Feb, 2013. 